\title{
Upward Turbulent Flame Spread
}

\author{
K. SAITO \\ Department of Mechanical and Aerospace Engineering \\ Princeton University \\ Princeton, New Jersey 08544, USA
}

\section{J. G. QUINTIERE}

Center for Fire Research

National Bureau of Standards

Gaithersburg, Maryland 20899, USA

\section{F. A. WILLIAMS}

Department of Mechanical and Aerospace Engineering

Princeton University

Princeton, New Jersey 08544, USA

\section{ABSTRACT}

Mechanisms and rates of upward spread of turbulent flames along thermally thick vertical sheets are considered for both noncharring and charring fuels. By addressing the time dependence of the rate of mass loss of the burning face of a charring fuel, a linear integral equation of the Volterra type is derived for the spread rate. Measurements of spread rates, of flame heights and of surface temperature histories are reported for polymethylmethacrylate and for Douglas-fir particle board for flames initiated and supported by a line-source gas burner, with various rates of heat release, located at the base of the fuel face. Sustained spread occurs for the synthetic polymer and not for the wood. Comparisons of measurements with theory aid in estimating characteristic parameters for the fuels.

\section{INTRODUCTION}

Upward flame spread on vertical surfaces is a critical aspect of accidental fires because of its inherent high speed and potential consequences of fire growth to surroundings. Many flammability test methods are configured to represent this hazard and attempt to assess the relative contribution for a material. Unfortunately no general test prescription exists to allow the prediction of a materia1's performance in upward flame spread. To that end, some research has been performed which can provide some guidance for achieving a generally applicable predictive model for upward spread.

Reviews on flame spread have included consideration of research on upward propagation. 1 There have been a number of theoretical and experimenta1 investigations related to the subject of concurrent or upward spread.2-13 Some of these concern spread along thermally thin materials, while others address thermally thick materials at scales (e.g., flame height) small enough for the spread processes to involve laminar flow. Here we are interested in thermally thick fuels that also are so thick that they are not completely consumed during the spread process, and we study planar two-dimensional upward spread at scales large enough for the flow to be turbulent. The systematic measurements of Kishitani et a1. I3 were performed on polymethylmethacrylate and chipped-wood samples $25 \mathrm{~cm}$ high, a size corresponding approximately to conditions for onset of turbulence. The only earlier experiments on two-dimensional spread that lie well within the regime of turbulent flow are those of orloff et al. ${ }^{3}$, who employed polymethylmethacrylate slabs $356 \mathrm{~cm}$ high. 
A motivation for the present study is to extend these turbulent-spread measurements to different materials and to different conditions of ignition. Transient pyrolysis of solids during upward spread contributes to making the process highly unsteady. The local mass-loss rates of thermoplastics will increase somewhat with time, while for charring materials they will eventually decrease with time. Indeed, because of this, Delichatsios ${ }^{14}$ suggests the existence of critical conditions for the occurrence of upward spread on vertical charring walls. In view of the possibility of the absence of spread, in the present experiments a diffusion-flame $\left(\mathrm{CH}_{4}\right)$ line-burner was used at the base of the vertical sample to promote sustained spread. Results of measurements are reported herein for both polymethylmethacrylate and chipped wood. As a basis for interpretation of the experimental results, a theoretical development is first given that includes consideration of spread along charring fuels. The experiments and their results are then presented, and comparisons with theory are discussed.

\section{THEORETICAL CONSIDERATIONS}

\subsection{Description of Normal Regression}

Charring materials pose severe difficulties in attempts to describe their combustion. The complexity of normal burning of charring fuels is reflected in simplified models thereof. 14-18 our current understanding of normal regression accompanied by char formation is incomplete, and more research on the subject is needed. The studies that have been performed demonstrate clearly that even under a constant rate of energy input the gasification rate remains time dependent. The rate of mass loss per unit area $\dot{m}^{\prime \prime}$ as a function to time $t$ (at a fixed location $x$ ) for a thick cellulosic material, whose face is exposed to a constant energy flux beginning at $t=0$, is shown schematically in Fig. 1 as curve 0 . A rough approximation to experimental observations is $\dot{m}^{\prime \prime}=\dot{\mathrm{m}}^{\prime \prime}=$ constant during a fixed gasification time $t_{b}$ and zero otherwise, as illustrated in curve 1 . Alternatively, various model simplifications ${ }^{14,18}$ lead to the theoretically predicted inverse square-root dependence on $t-t_{0}$ indicated in the figure as curve 2 . As a basis for describing upward spread we shall assume that after ignition each surface element of fuel exhibits the same gasification-rate history $\dot{m}^{\prime \prime}\left(t-t_{0}\right)$, independent of the location of the element. Although a general functional form of the relationship will be permitted in the analysis, the two simplified models illustrated in Fig. 1 as curves 1 and 2 will be kept in mind.

Responses of non-charring materials such as polymethylmethacrylate to constant rates of energy input are approximated well by curve 1 of Fig. 1 with $t_{b}=\infty$. Therefore the influence of charring can be viewed as providing a growing protective layer that introduces a finite characteristic gasification time $t_{b}$ (or $t_{c} \approx t_{b} / 2$ ) for the material. If the rate of energy input were to vary with time then $\dot{\mathrm{m}}^{\prime \prime}\left(t-t_{0}\right)$ would change accordingly, but a universal function still could exist. Therefore the hypothesis appears to have appreciable versatility. The additional complications associated with addressing questions of spread motivate the somewhat phenomenological level of description of the charring process adopted here.

\subsection{Description of Spread Mechanisms}

Spread occurs as a consequence of heating of the unignited portion of the fuel to a temperature at which vigorous pyrolysis begins. This heating is produced by convective and radiative heat transfer from the flames that bathe the fuel surface. Let $x$ denote the vertical distance along the fuel surface, with $x=0$ at the base of the fuel, $x=x_{p}$ at the upper edge of the pyrolysis region and $x=x_{f}$ at the average height of the visible flame tip, as illustrated in Fig. 1. The heat transfer responsible for spread occurs in the region $x \geq x_{p}$. Over the size range of the 


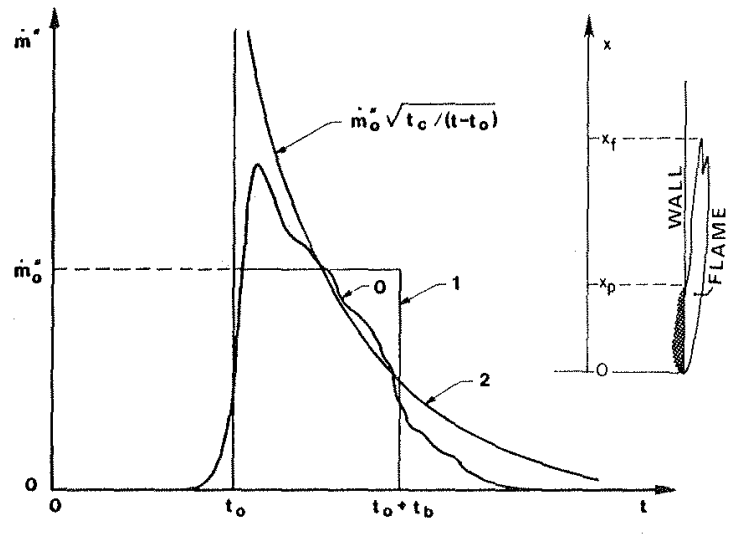

FIGURE 1.

I1lustration of gasification response to a constant heat flux for a charring material and of the spread model.

experiments to be reported herein, for steady-state burning at the base of a vertical wall, the energy flux $\dot{q}^{\prime \prime}$ to the wall has been found experimentally ${ }^{19}$ to correlate with $\mathrm{x} / \mathrm{x}_{f}$, and in a rough first approximation $\dot{q}^{\prime \prime}=\dot{q}_{0}^{\prime \prime}=$ constant $\approx 2.5 \mathrm{~W} / \mathrm{cm}^{2}$ for $0<x<x_{f}$ and $q^{\prime \prime}=0$ otherwise, so that $x_{f}$ is a good measure of the distance over which the principal heat transfer occurs.

If this rough approximation is employed along with the further assumption that $x_{f}-x_{p}$ remains approximately constant during spread, then the upward spread velocity of the pyrolysis front is

$v_{p}=4\left(\dot{q}_{o}^{\prime \prime}\right)^{2}\left(x_{f}-x_{p}\right) /\left[\pi k p c\left(T_{p}-T_{a}\right)^{2}\right]$,

where $k, p$ and $c$ are the thermal conductivity, density and heat capacity, respectively, of the fuel, and $T_{a}$ and $T_{p}$ are the ambient and ignition (or pyrolysis) temperatures of the fuel. Equation (1) can be rewritten as

$v_{p}=\left(x_{f}-x_{p}\right) / \tau$,

where the characteristic ignition time $\tau$ for spread depends only on fuel properties, the ambient temperature and the level of the heat flux to the fuel from the flame. As a simplification for describing time-dependent spread, we assume that Eq. (2) continues to apply with $x_{f}-x_{p}$ variable and that $\tau$ remains an approximately constant time characteristic of upward spread. Since Eq. (2) is not precisely derivable from the appropriate heat-conduction problem under the assumptions that have been introduced, its applicability will be tested herein from the spread data.

\subsection{Flame-Height Correlations}

Having hypothesized that the correlation of the heat-flux distribution with $\mathrm{x} / \mathrm{x}_{\mathrm{f}}$ may lead to Eq. (2), we need an expression for $x_{f}-x_{p}$ to obtain $v_{p}$. By definition

$x_{p}(t)=x_{p o}+\int_{0}^{t} v_{p}\left(t_{p}\right) d t_{p}$

where $x_{p o}$ is the value of $x_{p}$ at an initial time $t=0$, and $t_{p}$ is the dumm variable of integration. Flame-height correlations are required for obtaining $x_{f}$ : We allow for a pilot flame at the base of the wall releasing energy at the rate ' $\dot{Q}^{\prime}$ per unit 


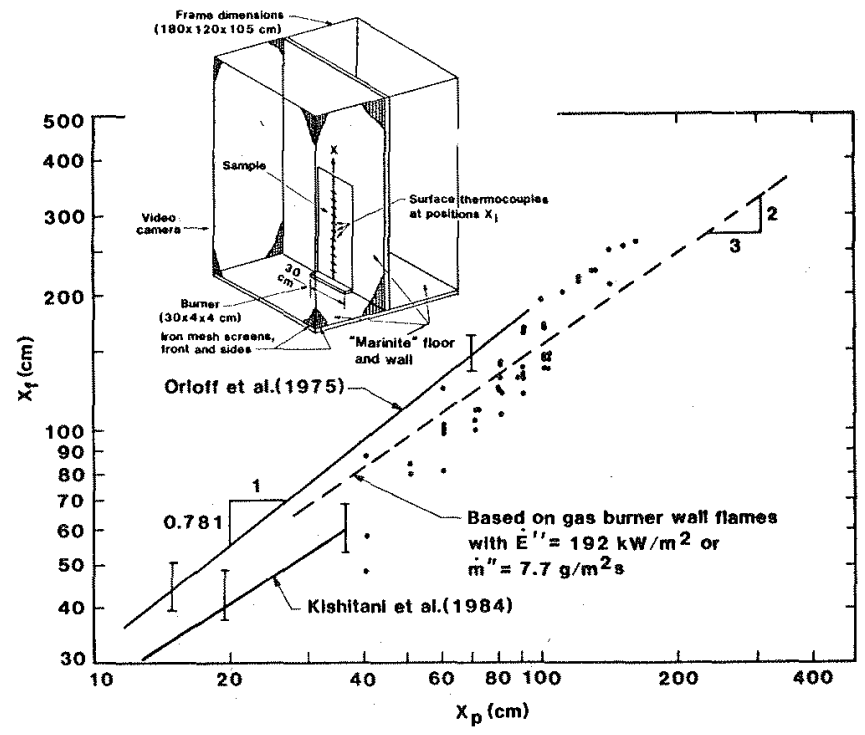

FIGURE 2.

Flame-height correlations with pyrolysis height for upward spread along thick sheets of polymethylmethacrylate, and schematic diagram of the experiment.

length. The total rate of energy release per unit length then is the sum $\dot{0}+$ $\mathrm{q} \int_{0}^{\mathrm{x}} \mathrm{m}^{\prime \prime} \mathrm{dx}$, where $\mathrm{m}$ ". is the previously introduced rate of mass loss per unit area of the fuel, and $q$ is the heat released per unit mass of fuel consumed. Flame-height correlations are of the form

$\mathrm{x}_{\mathrm{f}}=\mathrm{K}\left[\dot{Q}^{\prime}+\mathrm{q} \int_{0}^{\mathrm{x}} \mathrm{p} \dot{\mathrm{m}}^{\prime \prime} \mathrm{dx}\right]^{\mathrm{n}}$,

where $\mathrm{K}$ and $\mathrm{n}$ are constants. Experiments on steady wall flames, over the size range of interest here, support $\mathrm{Eq}$. (4) with $\mathrm{n}=2 / 3.19$ It is found that $\mathrm{K} \approx 1 \mathrm{~cm} /(\mathrm{W} / \mathrm{cm})^{2 /}$ for flames on open walls, while $\mathrm{K}$ is about $25 \%$ larger than this for flames on walls protected by side walls. Data for polymethylmethacrylate with $Q^{\prime}=0$ are useful for testing the applicability of Eq. (4) during upward spread because $\dot{\mathrm{m}}^{\prime \prime}$ is approximately constant for the burning portion of this fuel, so that $\mathrm{x}_{f}$ becomes proportional to $x_{p}^{n}$ according to Eq. (4). Results from orloff et a1. 3 , from Kishitani et aI. ${ }^{13}$ and from the present study are shown in Fig. 2. The methods employed for obtaining the present results will be described later.

It is seen from Fig. 2 that the slopes of the curves from the spread experiments tend to exceed those for steady wall burning. This may be caused by higher pyrolysis rates in the region of increased heat flux at the upper part of the pyrolyzing fuel during spread. The approach to a lower slope at large $x_{p}$ in the data of Kishitani et al. may be attributable to effects of the thickness of the fuel sheet (only $4 \mathrm{~mm}$ ). That the data of orloff et al. lie above ours is consistent with the fact that side walls were employed in their experiments but not in ours. From Fig. 2 it may be seen that within the accuracy of our data the exponent $n$ in Eq. (4) may be taken to be unity if $\dot{Q}^{\prime}=0$. Increasing $\dot{Q}^{\prime}$ would be expected to decrease $n$ toward the steady-state value of $2 / 3$, shown by the dashed line in Fig. 2. Even for situations under which $n$ approaches $2 / 3$, use of $n=1$ in $\mathrm{Eq}$. (4) may be thought to provide roughly correct theoretical predictions and sometimes will be introduced below for simplification.

For use in Eq. (2) a power-Iaw dependence of $x_{f}-x_{p}$ would be simpler than that of $\mathrm{x}_{\mathrm{f}}$ in Eq. (4). Unfortunately, the data show correlations for $\mathrm{x}_{f}-\mathrm{x}_{\mathrm{p}}$ to be appreciably poorer. 


\subsection{Predictions of Spread Histories for Noncharring Fuels}

For a noncharring fuel the application of Eqs. (2), (3) and (4) is relatively straightforward. Since $v_{p}=d_{p} / d t$ and $\dot{m}^{\prime \prime}$ is approximately independent of $x$ in the range $0<x<x_{p}$, we obtain the first-order ordinary differential equation

$\mathrm{dx}_{\mathrm{p}} / \mathrm{dt}=\left[\mathrm{K}\left(\dot{\mathrm{Q}}^{\prime}+\dot{\mathrm{E}}^{\prime \prime} \mathrm{x}_{\mathrm{p}}\right)^{\mathrm{n}}-\mathrm{x}_{\mathrm{p}}\right] / \tau$,

where $\tau, n, K$ and $\dot{E} "=\dot{q}^{\prime \prime}$ are taken as known constants, and the pilot rate $\dot{Q}^{\prime}$ is a known, experimentally adjustable function of time. For $n=1$ this equation is linear and easily solved; $x_{p}$ always increases linearly with $t$ at early.times. (if $x_{f o}>x_{p o}$

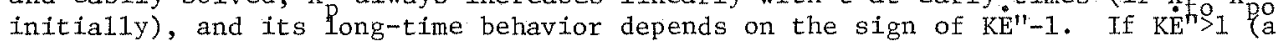
condition applicable, for example, to polymethylmethacrylate which may be estimated from $\mathrm{Fig} .2$ to have $\mathrm{KE}^{\prime \prime} \approx 2$ ) then $\mathrm{x}_{\mathrm{p}}(\mathrm{t})$ is acçeleratory, and an exponential increase of $x_{p}$ with $t$ is approached when $x_{p} \gg \dot{Q}^{\prime} / \dot{E}^{\prime \prime}$ is reached. If $K \dot{E}^{\prime \prime}<1$ (a condition unlikely to be realistic for noncharring fuels since $x_{f}$ unaugmented by a pilot would be less than $x_{p}$ ) then $x_{p}(t)$ is deceleratory [unless forced by an acceleratory $\left.\dot{Q}^{\prime}(t)\right]$, and eventually propagation of the pyrolysis front is predicted to cease at $\mathrm{x}_{\mathrm{p}}=\mathrm{KQ}^{\prime} /\left(1-\mathrm{KE}^{\prime \prime}\right)$, corresponding to $\mathrm{x}_{\mathrm{f}}=\mathrm{x}_{\mathrm{p}}$. However, if $\mathrm{Eq}$. (2) remains valid then the flame-height correlation of $\mathrm{Eq}$. (4) with $\mathrm{n}<1$ certainly must fail for noncharring fuels before $\mathrm{Eq}$. (5) gives $\mathrm{x}_{\mathrm{f}}=\mathrm{x}_{\mathrm{p}}$.

For $\mathrm{n}<1$ the implications of $\mathrm{Eq}$. (5) are qualitatively similar in most respects to those just decribed for $n=1$; the only significant difference is that, unless $Q^{\prime}(t)$ is sufficiently strong1y acceleratory, at sufficiently long times there is always a deceleration with an approach to a constant value of $x_{p}$. This may be seen directly, for example, from the explicit solution for $\dot{Q}^{\prime}=0$ and $n=2 / 3$, $v i z$,

$x_{p}=\mathrm{K}^{3}\left(\dot{\mathrm{E}}^{\prime \prime}\right)^{2}\left\{1-\left[1-\mathrm{x}_{\mathrm{po}}^{1 / 3} /\left(\mathrm{K} \dot{\mathrm{E}}^{\prime 2 / 3}\right)\right] \mathrm{e}^{-\mathrm{t} / 3 \tau}\right\}^{3}$ which exhibits a cubic acceleration, $x p \sim t^{3}$, at smal1 values of $t / \tau$ if $x$ is suf-
ficient1y sma11, but which always predicts that as $t / \tau \rightarrow \infty, x_{p} \rightarrow K^{3}\left(E^{\prime \prime}\right)^{2}$, pith $\mathrm{dx}_{\mathrm{p}} / \mathrm{dt} \rightarrow 0$. More genera11y, Eq. (5) indicates that always $\mathrm{dx} p / \mathrm{dt}=0$ when

$\mathrm{x}_{\mathrm{p}} / \mathrm{x}_{\mathrm{p} \infty}=\left(1+\mathrm{A} \mathrm{x}_{\mathrm{p}^{\infty}} / \mathrm{x}_{\mathrm{p}}\right)^{\mathrm{n} /(1-\mathrm{n})}$,

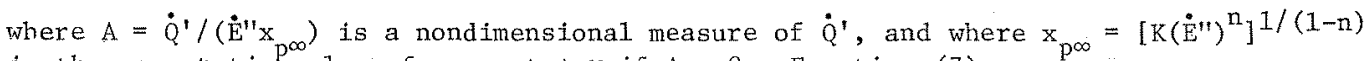
is the asymptotic value of $x_{p}$ as $t \rightarrow \infty$ if $A=0$. Equation (7) possess a unique solution that approaches $x_{p}=x_{p \infty}[1+A n /(1-n)+\ldots]$ for $A<<1$ and $x_{p}=x_{p \infty}$ $\mathrm{A}^{\mathrm{n}}\left(1+\mathrm{n} / \mathrm{A}^{1-\mathrm{n}}+\ldots\right)$ for $\mathrm{A}>1$. Whenever $\mathrm{dx}_{\mathrm{p}} / \mathrm{dt} \rightarrow 0$ is encountered with this formulation the situation corresponds to $\mathrm{x}_{\mathrm{f}} \rightarrow \mathrm{x}_{\mathrm{p}}$, and either $\mathrm{Eq}$. (2) or the flameheight correlation necessarily becomes invalid. Therefore use of the model for noncharring fuels should be restricted to conditions under which acceleratory propagation is predicted therefrom.

\subsection{Predictions of Spread Histories for Charring Fuels}

For a charring fuel the use of Eqs. (2), (3) and (4) is more complicated because of the variation of "m" with $x$ in Eq. (4). As an idealization of the present experiments assume that a constant value of $\dot{Q}^{\prime}$, say $\dot{Q}_{0}^{\prime}$, is employed to ignite the fuel and that the igniter provides a constant energy lux to the fuel over the flame height $\mathrm{KQ}_{\mathrm{O}}^{\mathrm{m}}$ and zero flux elsewhere, leading to an initial pyrolysis height $\mathrm{x}_{\mathrm{po}}=\mathrm{K} \dot{\mathrm{Q}}^{\mathrm{n}}$ at the time of ignition, taken to be $\mathrm{t}=0$. The initial condition for integration then will be $\mathrm{x}_{\mathrm{p}}=\mathrm{x}_{\mathrm{po}} \equiv \mathrm{K}_{\mathrm{o}}^{\mathrm{n}}$, with $\mathrm{x}_{\mathrm{f}}=\mathrm{x}_{\mathrm{f}_{\mathrm{o}}} \equiv \mathrm{K}\left[\dot{\mathrm{Q}}^{\prime}(0)+\mathrm{q} \dot{\mathrm{m}}^{\prime \prime}(0) \mathrm{x}_{\mathrm{po}}\right]^{\mathrm{n}}$, where $\dot{m}^{\prime \prime}(0)$ is the value of the universal function $\dot{m}^{\prime \prime}\left(t-t_{0}\right)$ from $F i g$. 1 at $t=t_{0}$. Likely in correspondence with physical reality for most experiments, we assume that $\mathrm{K}\left[\mathrm{qm}^{\prime \prime}(0) \mathrm{x}_{\mathrm{po}}\right]^{\mathrm{n}}>\mathrm{x}_{\mathrm{po}}$, so that the initial pyrolysis-front velocity, $\mathrm{v}_{\mathrm{po}}=\left(\mathrm{x}_{\mathrm{fo}}-\mathrm{x}_{\mathrm{po}}\right) / \tau$, is positive even po' the pilot is turned of at the instant of ignition [i.e., 
even if $\left.\dot{Q}^{\prime}(0)=0\right]$. If this condition is not satisfied then unaugmented spread cannot occur, and the formulation is inappropriate, at least if $\dot{Q}^{\prime}(0)$ is too small, as discussed earlier for noncharring fuels; note that if $n<1$ then in principle it is always possible to select $\dot{Q}_{0}^{\prime}$ large enough to give a value of $x_{\text {po }}$ too large to satisfy this condition.

"The integral in $\mathrm{Eq}$. (4) may be written as

$\int_{0}^{x_{p}} \dot{m}^{\prime \prime} d x=\int_{0}^{x_{p o}} \dot{m}^{\prime \prime} d x+\int_{x_{p o}}^{x_{p}} \dot{m}^{\prime \prime} d x=x_{p o} \dot{m}^{\prime \prime}(t)+\int_{0}^{t} \dot{m}^{\prime \prime}\left(t-t_{p}\right) v_{p}\left(t_{p}\right) d t_{p}$,

where $v_{p}\left(t_{p}\right)=(d x / d t) t_{t p}$ is the velocity of the pyrolysis front at time $t_{p}$. Substitution of $\mathrm{Eq}$. (8) into $\mathrm{Eq}$. (4), followed by substitution of this result and of Eq. (3) into Eq. (2), gives a nonlinear integral equation for $v_{p}(t)$. Here we sha11. write the result only under the further approximation that $\mathrm{p}=1$, in which case the integral equation becomes linear. Thus,

$v_{p}(t)=v_{p o}+\left\{\int_{0}^{t}\left[K q \dot{m}^{\prime \prime}\left(t-t_{p}\right)-1\right] v_{p}\left(t_{p}\right) d t_{p}-K q\left[\dot{m}^{\prime \prime}(0)-\dot{m}^{\prime \prime}(t)\right] x_{p o}-K\left[\dot{Q}^{\prime}(0)-\dot{Q}^{\prime}(t)\right]\right\} / \tau$.

With the nondimensionalizations $\xi=t / \tau, \xi^{\prime}=t_{p} / \tau$ and $v(\xi)=v_{p}(t) / v_{p o}$, Eq. (9) can be written as

$V(\xi)=\int_{0}^{\xi} F\left(\xi-\xi^{\prime}\right) \mathrm{V}\left(\xi^{\prime}\right) \mathrm{d} \xi^{\prime}+G(\xi)$,

where the kernel is

$F(\xi)=\operatorname{Kqm}^{\prime \prime}(t)-1$,

and the forcing term is

$\left.G(\xi)=1-\mathrm{Kq}_{\dot{\mathrm{m}}} \dot{\mathrm{m}}^{\prime \prime}(0)-\dot{\mathrm{m}}^{\prime \prime}(\mathrm{t})\right] \mathrm{x}_{\mathrm{po}} /\left(\mathrm{x}_{\mathrm{fo}_{\mathrm{o}}}-\mathrm{x}_{\mathrm{po}}\right)-\mathrm{K}\left[\dot{Q}^{\prime}(0)-\dot{Q}^{\prime}(\mathrm{t})\right] /\left(\mathrm{x}_{\mathrm{fo}_{\mathrm{o}}}-\mathrm{x}_{\mathrm{po}}\right)$,

In which $x_{p o} /\left(x_{\text {fo }}-x_{p o}\right)=\left[\mathrm{Kqm}^{\prime \prime}(0)\right]^{-1}$ if $\dot{Q}^{\prime}(0)=\dot{Q}_{0}^{\prime}$. Equation (10) is seen so be nonhomogeneous and of the volterra type.

To gain an understanding of the character of the solution to Eq. (10) consider first the early-time behavior for $\xi<<1$. Since the assumption that $v_{p o}>0$ for $Q^{\prime}(0)=0$ translates with $\mathrm{n}=1$ to $\mathrm{Kqm}^{\prime \prime}(0)>1$, we see that $\mathrm{F}(0)>0$, so that the shorttime solution to $\mathrm{Eq}:(10)$ becomes $V(\xi)=1+\left[F(0)+G^{\prime}(0)\right] \xi+\ldots$, where $G^{\prime}(0)=\left(K / v_{p o}\right)$ $\left[\mathrm{qx}_{\mathrm{po}}\left(\mathrm{dm}^{\prime \prime} / \mathrm{dt}\right)_{0}+(\mathrm{dQ} / \mathrm{dt})_{0}\right]$, in which the subscripts o on the derivatives mean that they are to be evaluated at $t=0+$. If $\dot{Q}^{\prime}(t)=\dot{Q}^{\prime}(0)$ then $d \dot{Q}^{\prime} / d t=0$, and from $F i g$. 1 it is then seen that $G^{\prime}(0)$ will be zero or negative [since ( $\mathrm{dm}^{\prime \prime} / \mathrm{dt}$ ) o becomes zero or negative]. Thus, the initial motion of the pyrolysis front is acceleratory, i.e., $v_{p y}(t)$ increases with $t$, if $F(0)+G^{\prime}(0)>0$, i.e., if [when $\left(\mathrm{dQ}^{\prime} / \mathrm{d} t\right)=0$ ] $\mathrm{Kqm}^{\prime \prime}(0)>$ 1. $-\mathrm{Kq}\left(\mathrm{dm}^{\prime \prime} / \mathrm{dt}\right)_{\mathrm{o}}\left(\mathrm{x}_{\mathrm{po}} / \mathrm{v}_{\mathrm{po}}\right)$. This condition holds true for curve 1 of $\mathrm{Fig}$. 1 , which has $\left(\mathrm{dm}^{\prime \prime} / \mathrm{dt}\right)=0$. It could be violated by a rapid initial rate of decrease of the gasification rate, like that of curve 2 of Fig. 1; curve 2 itself cannot be used here as $t \rightarrow t$ because it has $\dot{m}^{\prime \prime}(0)=\infty$ and therefore an infinite initial flame height. The observed experimental behavior of the gasification rate near $t=t_{0}$ (curve 0 of Fig.1) strongly suggests that $\mathrm{Kqm}^{\prime \prime}(0)>1-\mathrm{Kq}\left(\mathrm{dm}^{\prime \prime} / \mathrm{dt}\right)_{\mathrm{o}}\left(\mathrm{x}_{\mathrm{po}} / \mathrm{v}_{\mathrm{po}}\right)$ and that therefore the initial pyrolysis-front motion is acceleratory. In effect, at early times the extent of char-layer buildup is insufficient to decrease the gasification rate significantly, and the starting behavior is much like that of a noncharring fuel.

Although the initial development is expected to be acceleratory, the longtime behavior may differ appreciably from that of a noncharring fue1; a genuine tendency toward deceleration now may occur. To see this, first observe that in the absence of a strongly acceleratory driving pilot, $G(\xi)<1$ at sufficiently large values of $\xi$. Therefore if $V(\xi)$ has grown to a value sufficiently greater than 
unity, the nonhomogeneous term must become relatively unimportant in Eq* (10). Also, the ear1y-time history becomes irrelevant, so that the lower limit of the integral effectively may be extended to $\xi^{\prime}=-\infty$. The equation then admits a solution of the form $V(\xi)=V_{0} e^{\alpha \xi}$, which by substitution requires

$\int_{0}^{\infty} \mathrm{F}(\xi) \mathrm{e}^{-\alpha \xi} \mathrm{d} \xi=1$

This integral formula determines $\alpha$ in terms of nondimensional parameters, a $\equiv$ Kqm" $_{0}^{\prime \prime}$ and $b \equiv t_{b} / \tau$, characteristic of the charring history.

For curve 1 of Fig. 1, use of Eq. (11) in Eq. (13) and evaluation of the integral gives

$1+\alpha=a\left(1-e^{-\alpha b}\right)$,

while curve 2 , with the selection $t_{c}=t_{b} / 2$, gives

$1+\alpha=\sqrt{\pi / 2}$ a $\sqrt{b} \sqrt{\alpha}$.

Necessary conditions for solutions $\alpha(>0)$ to exist are $a b>(1+b)+\ln (a b)$ for Eq. (14) and $a \sqrt{b}>2 \sqrt{2 / \pi}$ for $\mathrm{Eq}$. (15); both of these conditions require a sufficientiy high level of the pyrolysis rate (Kqmo) and a sufficiently large ratio of the pyrolysis time to the spread time $\left(t_{b} / \tau\right)$ for accelerating spread to occur. A simple criterion for continued acceleration, derived from the model corresponding to curve 2 of Fig. 1, is

$\mathrm{Kq} \dot{\mathrm{m}}_{\mathrm{o}}^{\prime \prime} \sqrt{\mathrm{t}_{\mathrm{c}} / \tau}>2 / \sqrt{\pi}$

which involves the pyrolysis rate more strongly than the burning time and is independent of the strength of the ignition source.

If the pyrolysis rate or duration is too small [e.g., if $\mathrm{Eq}$. (16) is violated], then instead of the long-time exponential growth, Eq. (10) predicts deceleration toward $v_{p}=0$. The maximum value of $V(\xi)$, achieved prior to deceleration, is seen from Eq. (10) to be defined by $V(\xi)=\left[-G^{\prime}(\xi)-\int_{0}^{\xi_{F}}\left(\xi-\xi^{\prime}\right) V\left(\xi^{\prime}\right) \mathrm{d} \xi^{\prime}\right] / F(0)$, where the primes on $F$ and $G$ indicate differentiation. The character of the deceleration depends on the functional form of $\dot{\mathrm{m}}^{\prime \prime}(t)$; spread may cease at a finite or infinite time. The kernel in Eq. (11) is not positive-definite but instead becomes negative at sufficiently large values of $\xi$, approaching -1 as $\xi \rightarrow \infty$. The nondimensional time of termination of spread, $\xi_{t}$, and the nondimensiona1 extent of spread, $x_{t} \equiv \int_{0} v(\xi) d \xi$, may be estimated from the criterion $\int \xi_{\mathrm{F}}\left(\xi_{\mathrm{t}}-\xi\right) \mathrm{V}(\xi) \mathrm{d} \xi=0$, obtained from $\mathrm{Eq}$. (10). For a pyrolysis response like curve 2 of Fig. 1, it appears that when Eq. (16) is yiolated the deceleration is slow enough to give $\xi_{t}=\infty$, and for large values of $\xi_{,} \xi^{\prime} V\left(\xi^{\prime}\right) d \xi^{\prime}$ $\rightarrow X_{t}-$ const. $/ \sqrt{\xi}$, so $V \rightarrow$ const. $/ \xi^{3 / 2}$. Further study of Eq. (10) could ald in further clarification of both acceleratory and deceleratory upward spread of flames along charring fuels.

\section{EXPERIMENTAL DESIGN}

In the experiments the $\mathrm{CH}_{4}$ flow rate to the pilot burner at the base of the vertically mounted fuel samples was set and held at a fixed value, while thermocouple, video and visual observations were made. In some of the tests the burner (whose energy release rate was adjustable between 8.6 and $52 \mathrm{~kW}$ ) was turned off after ignition of the fuel was achieved.

Polymethylmethacrylate and (Douglas-fir particle-board) wood slabs $1.3 \mathrm{~cm}$ thick. were the materials employed. In the apparatus, sketched in Figure 2, the wood or 
plastic sample was flush-mounted and fixed to a larger vertical Marinite (inert) wa11. The sample and burner widths were $30 \mathrm{~cm}$. Despite possible three-dimensiona1. edge effects, the flow and propagation were observed to have a two-dimensional character. Screens provided shielding from laboratory drafts, and a video camera recorded the visible propagating flame. Surface thermocouples $(0.1 \mathrm{~mm}$ diameter, Chromel-Aiumel) were mounted along the sample vertical center-1ine such that their beads were just beneath the surface (i.e. within $\leq 1 \mathrm{~mm}$ of sample depth).

To define the pyrolysis front, auxiliary experiments of piloted ignition under radiative heating for nominally 2 to $6 \mathrm{~W} / \mathrm{cm}^{2}$ were performed and showed this thermocouple/sample response at the onset of flaming to yield temperatures of approximately $315 \pm 25^{\circ} \mathrm{C}$ for polymethylmethacrylate and $340 \pm 50^{\circ} \mathrm{C}$ for the particle-board sample. These temperature measurements also showed that the observed onset of bubbles in the polymethylmethacrylate samples occurred at a recorded temperature of about $320^{\circ} \mathrm{C}$. Subsequently on the basis of more detailed measurements of ignition times and ignition temperatures as functions of externally applied radiant energy flux, it was found that in the range of the ignition times of the spread experiment, temperatures $\mathrm{T}_{\mathrm{p}}$ for onset of pyrolysis may be taken as approximately $320^{\circ} \mathrm{C}$ for both fuels, a value consistent with temperatures at ignition measured by the lower thermocouples mounted on the sample (those adjacent to the pilot flame).

Methods considered for defining the flame-tip heights $x_{f}$ included detecting the onset of thermocouple temperature rise (e.g., $10^{\circ} \mathrm{C}$ above ambient), short-time averaging of measurements made from video records, selection of individual video frames equaliy spaced in time and direct visual estimates. The methods based on temperature had uncertainties in detecting. small temperature increases and in equating these to the presence of the flame tip rather than to influences of hot combustion products above the flame; the resulting values of $x_{f}$ exhibited the same trends as those of the other methods but were larger, and a temperature rise of $40^{\circ} \mathrm{C}$ provided best agreement of $x_{f}$ with results of other methods. The short-time averaging proved considerably more time-consuming but no more revealing than selection of individual frames, the method finally adopted. The results show oscillations in time about an evolving mean, with frequencies appreciably lower than would have been obtained had every frame been employed; i.e., the oscillations shown in $\mathrm{x}_{f}$ are indicative only of their magnitudes.

\section{EXPERIMENTAL RESULTS AND DISCUSSION}

Sustained upward propagation occurred for the plastic, over the entire range of burner energy-supply rates, irrespective of whether the burner was turned off after ignition. However, even with the burner left on for ten minutes, no wood sample exhibited sustained propagation. The maximumeight of the observed char (pyrolysis) front on the wood increased appreciably with increasing burner energysupply rates (but not greatly with test duration if the test was sufficiently long). Thus Eq. (16) must be violated for the wood.

Representative experimenta1 results are shown in Figs. 3 and 4 for the plastic and wood, respectively. For the plastic the first two thermocouple traces exhibit the temperature increase adjacent to the igniter flame; the remaining traces are similar to each other but displaced in time, showing upward pyrolysis propagation. For the wood the first two themocouple traces are not greatly different from those for the plastic, although a continued gradual increase in temperature at long times is observed, possibly indicative of continuing char combustion. However, the remaining traces for the wood are quite different, showing an increase to a maximum temperature and a cooling thereafter, even though the burner remained on; the maximum temperature increase of the uppermost thermocouple was less than $100^{\circ} \mathrm{C}$. Thus, by any criterion, the wood enhibited a maximum value of $x_{p}$, achieved at a finite time. 

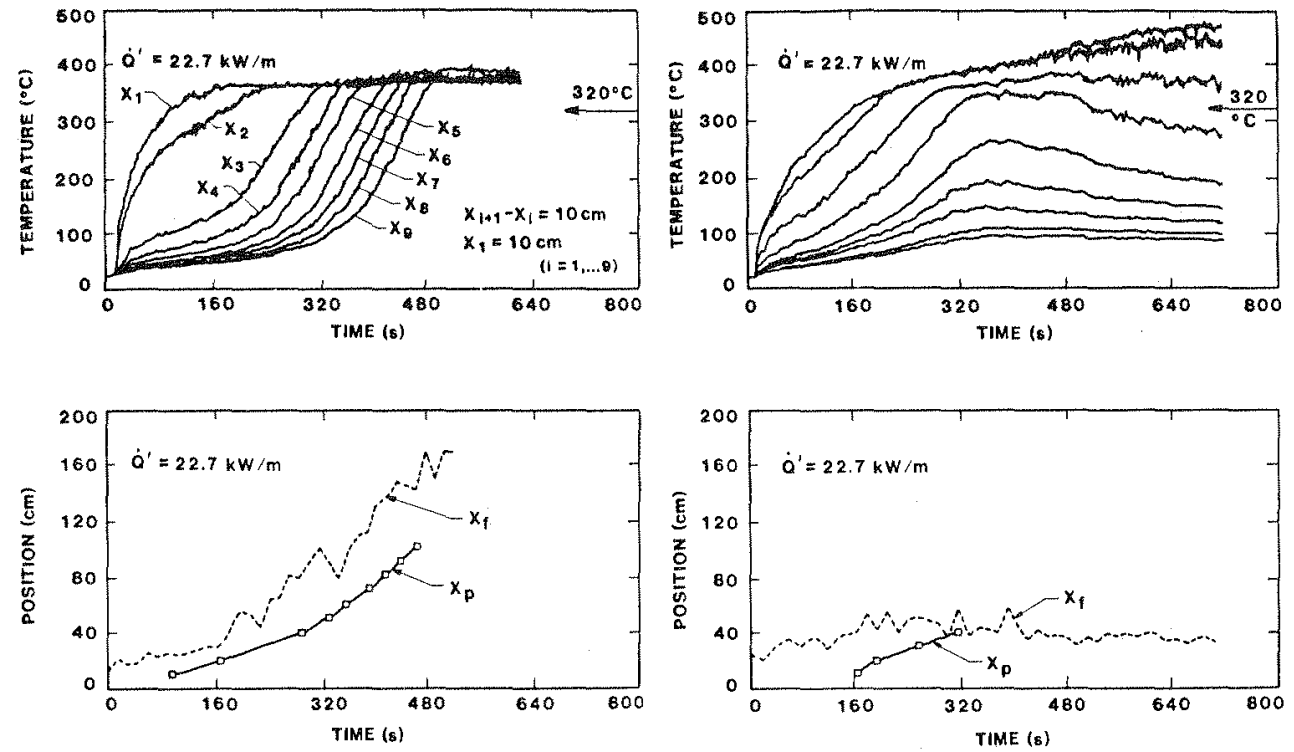

FIGURE 3. Representative thermocouple traces and histories of $\mathrm{x}_{\mathrm{f}}$ and $\mathrm{x}_{\mathrm{p}}$ for polymethylmethacrylate.

FIGURE 4. Representative thermocouple traces and histories of $x_{f}$ and $x_{p}$ for Douglas-fir particle board.

The histories of $\mathrm{x}_{\mathrm{p}}$ and $\mathrm{x}_{\mathrm{f}}$ shown in $\mathrm{Fig}$. 3 for the plastic are both quite representative of acceleratory spread. Spread velocities, obtained from curves Iike that of Fig. 3 for $x_{p}$, are shown in Fig. 5. It is seen that the data on spread with the burner turned of Within the accuracy of the measurements, the slope of a line through our data points in Fig. 5 could be unity, corresponding to an exponential increase of $v_{p}$ with time, as first identified by Orloff et a1. ${ }^{3}$ Thus, the data are consistent with $\mathrm{n}=1$ in Eqs. (4) and (5). However, the accuracy of the measurements is insufficient to conclude definitely that $\mathrm{n}=1$; a line of lesser slope would also be consistent with the data. In fact, within the accuracy of the measurements, Eq. (6) can correlate the data as well as any formula for $n=1$. From the data we cannot distinguish with certainty between an exponential and power-law increase in $x$ with time. Thus, we cannot draw conclusions about the applicability of steady-state flame-height correlations during spread.

From the results shown in Figs. 2 and 5 it is straightforward to calculate the $\tau$ of Eq. (2) for polymethylmethacrylate; $\tau=170 \mathrm{~s}$, with better than $5 \%$ accuracy. The observed spread histories are entirely consistent with Eq. (2) with a constant $\tau$; within the accuracy of the measurements. Moreover, the value obtained for $\tau$ from the spread measurements is consistent with that which would be obtained from Eq. (1), with the independently inferred value $\dot{q}^{\prime \prime} \approx 2.5 \mathrm{w} / \mathrm{cm}^{2}$, by independent estimates of properties of the polymer. Therefore the general understanding of the spread mechanism for polymethylmethacrylate is on firm ground; the uncertainties involve only the accuracy with which $\mathrm{Eq}$. (2) applies and the precise value of $\mathrm{n}$ in Eq. (4).

The burner-on data shown in Fig. 5 exhibit higher spread rates, as would be expected from Eq. (5), but are not accurate enough for conclusions to be drawn from numerical comparisons with theoretical predictions. 

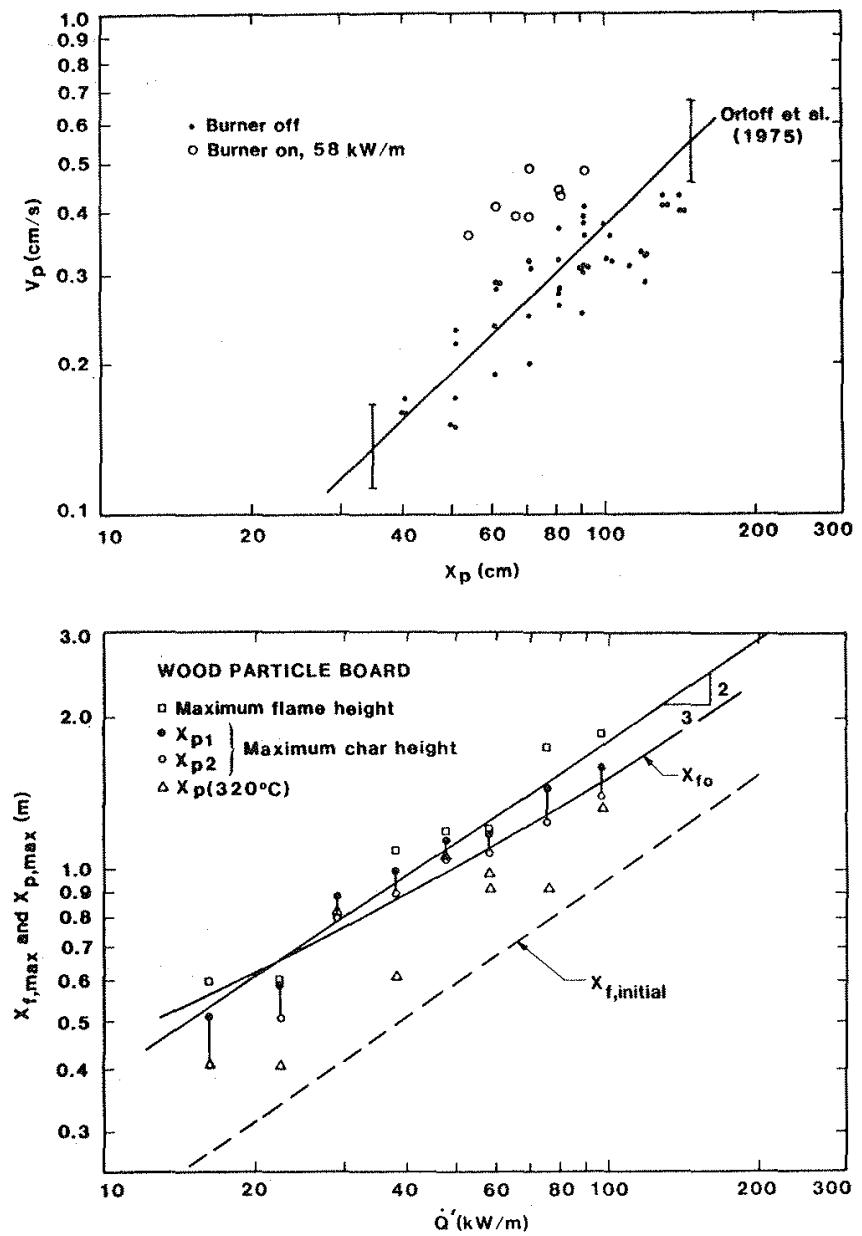

FIGURE 5 .

Spread rate as a function of pyrolysis position for polyme thylmethacrylate.

\section{FIGURE 6.}

Flame heights and pyrolysis heights for wood as functions of the burner energy-supply rate.

The histories of $x_{f}$ and $x_{p}$ shown in Fig. 4 for wood clearly are not indicative of acceleratory spread. Although theoretically there should be an initial period of acceleration, the measurements cannot be made with sufficient refinement to exhibit it. The deceleration of spread and its eventual cessation are clear from Fig. 4. After a small increase to a maximum value the $x_{f}$ curve exhibits a gradual decrease toward the initial value associated with the burner flame alone. The $x_{p}$ curve terminates at a maximum value that depends on the selection of $T$; the first two points on this curve (and on the corresponding curve of Fig. 3 as we11) should be ignored in making comparisons with the spread theories because they refer to positions below the initial burner flame-tip height. That the last six thermocouple traces peak at the same time is a good indication that flame propagation should be considered to cease before $x$ reaches these thermocouples. Thus, only one of the thermocouple traces in Fig. ${ }^{\mathrm{P}} 4$ definitely corresponds to a position above the initial flame-tip height $\left(x_{p o}\right)$ and below the final maximum value of $x_{p} \cdot$ The data therefore clearly are insulficient for testing theoretical predictions of the manner in which $v$ decelerates to zero. An estimate of an average value for $v$ can be obtained and reasonably compared with $\mathrm{v}_{\text {po }}$, defined above Eq. (8); uncertainties 
in $x_{f o}$ and in $\tau$ are great enough to make the agreement acceptable but the comparison nondefinitive.

Additional information obtainable from the results of the experiments with wood is shown in Fig. 6. Three different measures of the maximum value of $x_{\text {are }}$ shown, one based on attaining a thermocouple temperature of $320^{\circ} \mathrm{C}$, one ( $\mathrm{x}$ ) $\mathrm{p}_{\text {based }}$ on observed darkening of the wood, and one $\left(x_{p 2}\right)$ based on a 2 mm char-layer thickness (after termination of the experiment). Pt is seen that the first of the three measures gives values appreciably lower than the last two. This is consistent with the first being more relevant to spread and the charring at higher positions being produced by continued heating of the sample by the burner in these relatively long

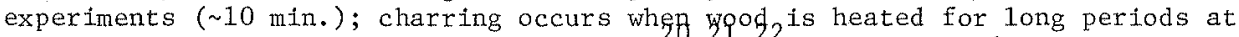
energy fluxes too low to produce ignition. ${ }^{2}, 21,2$ with the $320^{\circ} \mathrm{C}$ points used to identify the maximum value of $x$, it is seen from Fig. 6 that if the initial value of $\mathrm{x}_{\mathrm{f}}$ is equated with $\mathrm{x}_{\mathrm{po}}$, as indicated above $\mathrm{Eq}$. (8), then the total extent of spread is small (e.g., $\mathrm{x}^{-\mathrm{x}}<\mathrm{x}_{\mathrm{x}}$ always). For the wood we may estimate $170 \mathrm{~s}$ $\lesssim \tau<350 \mathrm{~s}, 300 \mathrm{~s} \lesssim \mathrm{t}_{\mathrm{p}} \underset{\sim}{\mathrm{p}} 888 \mathrm{~s}($ (3o $150 \mathrm{~s} \lesssim \mathrm{t} \mathrm{c} \lesssim 400 \mathrm{~s}), \mathrm{K} \approx 0.01 \mathrm{~m} /(\mathrm{kJ} / \mathrm{m} \mathrm{s})$ (with

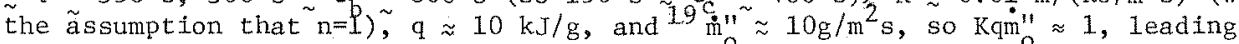
roughly to an equality in $\mathrm{Eq}$. (16); thus the wood should be marginally capable of continued propagation, and sufficiently intense external radiant energy input should lead to continued spread.

The maximum flame height shown in Fig. 6 is roughly twice the initial flame heighto The initial flame height correlates we11 with Eq. (4) with $n=2 / 3$, as it must. 19 Since the extent of spread is small we should expect the maximum $x_{f}$ to be close to the value $x_{f o}$ defined above Eq. (8); this is borne out, within the accuracies of the calculation and of the data, as seen in Fig. 6 . Because of the sma11 extent of spread, the power-law correlation for steady wall flames is much better for wood than for polymethylmethacrylate.

\section{ACKNOWLEDGEMENTS}

The authors wish to acknowledge the contributions of Ms. C. Carpentier and Ms. M. Harkleroad, who conducted the ignition experiments for identifying $\mathrm{T}_{i}$; Mr. A. Flores, who developed the computer programs for reducing the flame spread data; and $\mathrm{Mr}$. W. Rinkinen, who determined the flame heights from the video records and who assisted in the conduct of the flame-spread experiments. One author (FAN) wishes to acknowledge partial support from a National Sciences Foundation Grant ( INT -8403848 ).

\section{REFERENCES}

1. A. C. Fernandez-Pello and T. Hirano, Combustion Science and Technology 32 , 1 (1983).

2. G. H. Markstein and J. de Ris, Fourteenth Symposium (International) on Combustion, The Combustion Institute, Pittsburgh (1973), pp. 1085-1097.

3. L. Orloff, J. de Ris and G. H. Markstein, Fifteenth Symposium (Internationa1) on Combustion, The Combustion Institute, Pittsburgh (1975), pp. 183-192.

4. M. Sibulkin and J. Kim, Combustion Science and Technology 17, 39 (1977).

5. A. C. Fernandez-Pe11o, Combustion Science and Technology 17, 87 (1977).

6. A. C. Fernandez-Pe11o, Combustion and F1ame 31, 135 (1978). 
7. A. C. Fernandez-Pe11o, Combustion and Flame 36,63 (1979).

8. K. Annamalai and M. Sibulkin, Combustion Science and Technology $\underset{\sim}{19}$, 185 (1979).

9. R. L. Alpert, "Pressure Modeling of Vertically Burning Aircraft Materials," FAA-RD-78-139 (1979).

10. A. C. Fernandez-Pe11o and C. P. Mao, Combustion Sclence and Technology 26, 147 (1981).

11. L. Chu, C. H. Chen and J. S. T'ien, ASME paper No. 81-WA/HT -42 (1981).

12. G. Carrier, F. Fende11 and S. Fink, Combustion Science and Technology 32, 161 (1983).

13. K. Kishitani, S. Sugawara and K. Hamada, Saigai no Kenkyu 15, 133 (1984).

14. M. A. Delichatsios, ASME Paper No. 83-WA/HT-64 (1983).

15. D. B. Adarkar and I. B. Hartsook, AIAA Journal $\underset{\sim}{4}, 2246$ (1966).

16. H. C. Kung, "A Mathematical Model of Wood Pyrolysis," Factory Mutual Research Corporation, Report No. 19721-6 (1971).

17. R. C. Corlett and F. A. Williams, Fire Research 1 , 323 (1978).

18. M. A. Delichatsios and J. de Ris, "An Analytical Model for the Pyrolysis of Charring Materials," Factory Mutual Research Corporation, Report No. J.I. OkOJ1.BU (1983).

19. J. Quintiere, M. Harkleroad and Y. Hasemi, "Wa11 Flames and Implications for Upward Flame Spread," ATAA Paper No. 85-0456 (1985).

20. F. J. Kilzer and A. Broido, Pyrodynamies 2, 151 (1965).

21. F. A. Williams, Progress in Energy and Combustion Science 8, 317 (1982).

22. M. J. Anta1, Jr., "Biomass Pyrolysis: A Review of the Literature," Advances in Solar Energy p. 61 (1982). 